\title{
Effects of diet on behaviour and cognition in children
}

\author{
France Bellisle \\ Hôtel-Dieu, 1 Place du Parvis Notre-Dame, 75181 Paris, France
}

\begin{abstract}
Diet can affect cognitive ability and behaviour in children and adolescents. Nutrient composition and meal pattern can exert immediate or long-term, beneficial or adverse effects. Beneficial effects mainly result from the correction of poor nutritional status. For example, thiamin treatment reverses aggressiveness in thiamin-deficient adolescents. Deleterious behavioural effects have been suggested; for example, sucrose and additives were once suspected to induce hyperactivity, but these effects have not been confirmed by rigorous investigations. In spite of potent biological mechanisms that protect brain activity from disruption, some cognitive functions appear sensitive to short-term variations of fuel (glucose) availability in certain brain areas. A glucose load, for example, acutely facilitates mental performance, particularly on demanding, long-duration tasks. The mechanism of this often described effect is not entirely clear. One aspect of diet that has elicited much research in young people is the intake/omission of breakfast. This has obvious relevance to school performance. While effects are inconsistent in well-nourished children, breakfast omission deteriorates mental performance in malnourished children. Even intelligence scores can be improved by micronutrient supplementation in children and adolescents with very poor dietary status. Overall, the literature suggests that good regular dietary habits are the best way to ensure optimal mental and behavioural performance at all times. Then, it remains controversial whether additional benefit can be gained from acute dietary manipulations. In contrast, children and adolescents with poor nutritional status are exposed to alterations of mental and/or behavioural functions that can be corrected, to a certain extent, by dietary measures.
\end{abstract}

Nutrition: Cognition: Glucose: Breakfast: Micronutrients

\section{Introduction}

Adequate brain function is a prerequisite for efficient cognition and the performance of organized behaviour. Indeed, the uninterrupted activity of the brain is of vital importance to the survival of the organism since it ensures the continuous performance of many essential voluntary and involuntary functions. It is therefore imperative that the brain is protected from even short-term disruptions of its efficient working conditions. One crucial factor is the supply of metabolic fuel to the brain, in the form of glucose. Glucose supply to the brain is maintained by complex mechanisms involving several hormones and feedback loops to ensure that glycaemia is regulated and maintained at appropriate levels at all times. Given the existence of such potent biological safeguard mechanisms, mental activity that allows cognitive appreciation of the world and appropriate behavioural responses to environmental conditions should be protected from moment-tomoment fluctuations in nutritional status from one meal to the next, and, more generally, from variations in nutrient availability under a broad range of life situations, as long as major nutritional or energy insufficiencies do not occur.

Nevertheless, many studies suggest that poor nutritional status can indeed adversely affect brain function and impact on cognition and behaviour. To a certain extent, appropriate correction of nutrient deficiencies can indeed lead to measurable improvement. Moreover, recent findings suggest that, even in situations of adequate nutritional status, the brain can actually be sensitive to shortterm variation of glucose availability. The present paper reviews existing data illustrating such situations in children and adolescents. We first look at behaviour, defined in a very broad sense, and then review effects on various aspects of cognition. Short-term, immediate effects of the ingestion of certain nutrients or meals are considered, as well as longer-term effects attributable to the overall nutritional status of the organism. Scientific evidence is provided about the beneficial and detrimental effects of nutrients, ingredients, foods, meals, eating patterns, and overall nutritional status of the subject. Looking at the potential effects of nutritional factors on cognition and behaviour in young people is of special importance, because childhood and adolescence are crucial periods for acquiring factual knowledge as well as the behavioural and social skills that will determine the person's ability to cope with the many demands of modern society. This paper does not deal with the very important field of infant nutrition or the long-term effects of breast-feeding, which are beyond the scope of the present workshop. Most of the studies presented here involve school age populations.

\section{Behavioural effects}

What are the alleged and/or demonstrated effects of nutritional elements on the behaviour of children or

\footnotetext{
Abbreviation: IQ, intelligence quotient.

* Corresponding author: ILSI Europe, 83 Avenue E. Mounier, Box 6, B-1200 Brussles, fax + 3227620044 , email publications@ilsieurope.be
} 
adolescents? There is one major behavioural problem that has attracted much attention and has been associated with the presence of certain elements in the diet. The American Psychiatric Association (1994) calls this condition 'attention-deficit/hyperactivity disorder'. This problem is more frequent in boys than in girls and is often treated by pharmacological substances (Wolraich et al. 2001; Wilens et al. 2003). The affected children are described as overactive young people who cannot concentrate, cannot sit still, cannot keep silent, leave one activity unfinished and go to the next. According to proposed hypotheses, the aetiology of this disorder might have to do with intake of sugar, on the one hand, or food additives, on the other. Although observational studies did suggest potential associations, more rigorous intervention experiments did not confirm any causal role of either sugar or food additives in the presence or severity of the disorder.

\section{Hyperactivity and sugar intake}

Crook (1974) observed that when sucrose was eliminated from a hyperactive child's diet, behaviour improved, but symptoms returned when sugar was reintroduced. Rapp (1978) eliminated various foods including sucrose from the diet of hyperactive children. In a few cases, parents reported that hyperactive behaviour increased as sugar was reinstated. Based on these and other case studies, sugar came to be suspected as a major cause of hyperactivity. These studies, however, had major methodological problems, such as the absence of a control group or the lack of double-blind testing.

Correlational studies provide some support to the idea that sugar intake could play a role in hyperactivity. Prinz et al. (1980) found a correlation between sugar intake (as estimated from a food diary) and destructive-aggressive behaviours in hyperactive children, while a correlation appeared between sugar intake and activity in children of the control group. Wolraich et al. (1986) failed to find correlations between behaviour and sugar intake, although some of the evidence suggested that higher sugar:total energy was associated with elevated activity, off-task behaviours and attention shifts. In pre-school boys, Prinz \& Riddle (1986) found that children who consumed the largest amounts of sugar were less able to sustain attention in a vigilance test than peers who consumed the least amounts.

The majority of controlled experimental studies, however, do not support the notion that sugar intake leads to an increase in activity or hyperactivity. Studies comparing a sucrose challenge with a placebo (usually saccharin or aspartame) did not find differences in behaviours such as activity, impulsivity or locomotion (Wolraich et al. 1985; Ferguson et al. 1986; Roshon \& Hagen, 1989) even when the tests were carried out in children diagnosed with attention-deficit/hyperactivity disorder (Mahan et al. 1988; Wender \& Solanto, 1991). Some studies even reported a decrease in activity levels after intake of sucrose or glucose (Behar et al. 1984; Saravis et al. 1990). A few studies reported higher activity in children after high doses of sucrose (e.g. Rosen et al. 1988). Overall, the experimental evidence does not support a causal association between sucrose intake and activity (Logue, 1991). A reverse causality can also be envisaged, and has been explicitly enunciated in intake surveys: very active children need more energy than sedentary peers, and high sugar intakes serve to cover high energy needs (e.g. Deheeger et al. 1997).

\section{Hyperactivity and the presence of food additives in the diet}

Feingold (1977) hypothesized that hyperactivity was a child's adverse reaction to food additives, such as artificial sweeteners, artificial colours and preservatives, that are present in numerous industrial foods and drinks. He eliminated these substances from a dietary regimen that came to be known as 'the Feingold diet'. Tests of the benefits of the Feingold diet have yielded inconclusive results. For example, hyperactive and non-hyperactive children were fed the Feingold diet for five days (Swanson \& Kinsbourne, 1980). The children received a capsule with either a placebo or food dyes on days 4 and 5 and learning tasks were conducted on these days. The hyperactive children, but not the controls, performed worse after receiving the food dyes compared with placebo. This study used a relatively high dose of food dyes exceeding what a child would consume from the regular diet, so it is not certain that the results can be generalized to real-life situations. In another experimental study of hyperactive children fed the Feingold diet, Weiss et al. (1980) gave medium doses of food dyes on some days in a double-blind procedure. In only two of the twenty-two children were the mothers able to detect behavioural effects of the dyes. In the other twenty, food dyes had no discernible effect. So, some effect can appear in particularly sensitive individuals.

Obviously, food additives have changed enormously in the food supply since Feingold's original hypothesis. Whether or not some of those substances are causally related to hyperactivity in children or adolescents remains to be demonstrated. Given the high prevalence of the disorder and the long-term pharmacological treatment sometimes prescribed from a very young age (Wolraich et al. 2001; Wilens et al. 2003), the potential contribution of dietary substances to the problem deserves vigilant consideration.

\section{Thiamin}

Thiamin is a vitamin for which body stores are relatively small and can be depleted within a few weeks of inadequate intake. Behavioural problems have been reported in thiamin-deficient adolescents whose diet consists largely of high-calorie 'junk' food (Benton et al. 1997). The symptoms include irritability, aggressive behaviour and personality changes. The causal role of thiamin deficiency in the problem was demonstrated by the fact that treatment with thiamin alone resulted in behavioural improvement in patients who had previously failed to respond to drugs or psychotherapy. Thiamin status also appears to play a role in mental performance, as we shall see later.

\section{Cognitive effects}

Cognition represents a complex, multidimensional set of abilities. Validated tests assess specific dimensions of 
'intelligence'. Memory, reasoning, attention and psychomotor coordination are only a few of the functions that contribute to mental ability. Memory itself is a very complex set of processes (e.g. short-term, long-term, visual, spatial, verbal, declarative, semantic, strategic) that can be investigated using different assessment tools. In addition to the fundamental complexity of mental functions involved in any cognitive task, intellectual performance under specific test conditions depends on multiple factors, amongst which are individual skill, motivation, general arousal, previous learning, fatigue and time of day. Given the number and complexity of factors susceptible to affect cognitive performance at any particular moment, it is indeed not surprising that very few nutritional effects on cognition have received scientific support. Here we discuss the short-term beneficial effects of glucose intake, the short-term effects of breakfast consumption or omission, and the importance of adequate micronutrient status on various aspects of cognitive performance.

\section{Immediate effects - glucose}

An abundant literature suggests that some aspects of intellectual performance can be improved following the intake of a glucose load or some other carbohydrate-rich food. The majority of studies in this field have been carried out in adult subjects. A study by Benton et al. (1987) claimed that glucose does improve attention and reaction to frustration in children, suggesting that the mechanism involved could be the same whatever the age of the subject.

Typically, studies of glucose effects investigate several aspects of mental performance post-ingestion and use a battery of tests. Most studies report significant beneficial effects on some of the dependent measures, and no change in other measures, in the same subjects. It has become obvious that cognitive processes are not equally sensitive to enhancement following a given load of glucose. Positive effects have often been reported for various aspects of short-term memory, and other types of benefit have been demonstrated for rapid information processing, performance on the Stroop test, focused and sustained attention, maze learning, arithmetic ability (Benton et al. 1987), and long-term free and cued recall tasks (Foster et al. 1998). Among negative results, glucose ingestion produced no effect on digit span measures, digit recall or long-term non-verbal memory (Foster et al. 1998). The rise in blood glucose that follows a glucose drink correlates with improved decision time in a reaction time task, faster information processing, better word recall, and improvement on a cognitive conflict task (Benton \& Owens, 1993). The effects are not due to the correction of hypoglycaemia, since they are reproduced across a range of baseline blood glucose levels.

Why is it that some mental tasks are improved following the intake of glucose while others are not? Recent studies suggest that the degree of cognitive demand or mental effort required by a task may predict its susceptibility to enhancement by glucose and other metabolic substrates (Donohoe \& Benton, 1999; Kennedy \& Scholey, 2000). Demanding mental tasks are improved following a glucose load, compared with placebo. Easy tasks are not affected.
In mental tasks of long duration, the later phases of the tasks are likely to be improved by a glucose load, while the earlier phases are unaltered. The beneficial cognitive effects of a glucose load are particularly obvious in persons with some level of mental disability, such as patients with Alzheimer's disease (Craft et al. 1992, 1996; Messier \& Gagnon, 1996) or Down's syndrome (Manning et al. 1998).

What is the relevance of this knowledge to cognition in children and adolescents? Clearly, more research is needed to answer this question. The conditions and scope of any actual enhancement of mental functions by previous glucose intake in children should be investigated. Many variables should be considered: who might benefit, under what circumstances, over what time interval, and in what type of task.

The mechanism underlying the observed effects is of great importance here. The effects could be due to a rapid and important rise in blood glucose following the glucose load (Benton \& Owens, 1993). They could be due to glucose effects on insulin (Craft et al. 1994; Hoyer, 1997). Glucose could act as a cholinergic agonist and as an opioid antagonist (Rodriguez et al. 1999). Elucidation of the critical mechanism might help develop strategies for allowing children to maintain the optimal metabolic state that will facilitate learning and performance, particularly in situations of demanding and prolonged effort. Nutrition experts who would advise parents to feed their children pure glucose in order to optimize mental performance would understandably be met with some suspicion. The basic message that seems to emerge from the glucose literature is that the brain appears to be sensitive to short-term fluctuations of the glucose supply and therefore it might be beneficial to maintain glycaemia at adequate levels between meals to optimize cognition. This could potentially be achieved by a number of means. For example, it seems that low-glycaemic-index foods that minimize glycaemia fluctuations could facilitate mental performance in the hours that follow ingestion. A very recent report provides data in support of this hypothesis in adults (Benton et al. 2003).

\section{Immediate effects - breakfast}

One very developed field of study about child cognition is that of the effects of ingesting or omitting breakfast on learning ability in school (e.g. Dickie \& Bender, 1982; Pollitt et al. 1981, 1983; Connors \& Blouin, 1983; Simeon \& Grantham-McGregor, 1989; Michaud et al. 1991; Chandler et al. 1995; Wyon et al. 1997). For decades, educators have attributed the poor performance of many children in the classroom to inadequate nutrition and, more particularly, to the fact that children leave home without having breakfast and therefore cannot mobilize enough energy in the morning to cope with the demands of school activities. To correct this problem, school breakfast programmes have been implemented in several countries, in developing as well as in industrialized areas of the world. An undesirable side-effect of such programmes that has been observed repeatedly is that the 'school breakfast' actually duplicates the earlier breakfast 
that many children did consume at home and adds unneeded calories to the daily diet, sometimes aggravating weight control problems.

A symposium was devoted to Breakfast, Cognition, and School Learning in 1995. Its proceedings, published in the American Journal of Clinical Nutrition (Pollitt, 1998), stated that: "No definitive conclusions can be drawn from the existing data on either the long and short-term benefits of breakfast on cognition and school learning or the mechanisms that mediate this relation'. It was stressed that although omitting breakfast often interfered with cognition and learning, this effect was more pronounced in nutritionally at-risk children than in well-nourished children.

Although it might seem obvious to many that skipping breakfast can exert only deleterious effects on a child's cognitive ability, the actual data gathered under a variety of experimental circumstances show that breakfast omission sometimes has deleterious effects, has no effect or even has beneficial effects depending on what the task is, when it is performed after breakfast, the child's intelligence quotient (IQ), the child's age and nutritional status, and the child's habit of having or omitting breakfast. In addition to this, breakfast nutrient composition and size might also modify the observed changes in cognitive ability.

Breakfast interrupts the overnight fast and provides fuel to the brain and the whole organism. Young children might be more susceptible to the adverse effects of brief fasting than adolescents or adults, according to Pollitt et al. (1981), because of their greater brain metabolic demands relative to liver and muscle glycogen and to gluconeogenic capacity. Gibson \& Green (2002) have recently argued that much of the variation typically recorded in the effects of breakfast on performance might be due to uncontrolled individual differences in glycogen stores at the time of participation in the study.

\section{Immediate effects - snacks}

A few studies have suggested that the intake of a carbohydrate-rich snack in the afternoon can improve cognitive performance in adults (Kanarek \& Swinney, 1990; Kanarek, 1997). The potential effects of snacks of varying nutrient composition on the cognitive ability of children and adolescents have not yet been investigated.

\section{Long-term effects - vitamin status and intelligence score}

The vitamin status of children and adolescents has been shown to influence their cognitive ability. In the 1980s, a series of experiments suggested that vitamin supplements could improve IQ scores in children. For example, Colgan \& Colgan (1984) reported increased IQ scores in children with emotional and learning difficulties after taking micronutrient supplementation. Reading skill was also improved. Other reports confirmed these observations in British school children (Benton \& Roberts, 1988) and American adolescents (Schoenthaler et al. 1991). These encouraging findings were soon questioned by failed replications (Crombie et al. 1990; Nelson et al. 1990). Deeper investigations finally revealed that it is indeed possible to improve IQ scores in young people with micronutrient supplementation if, and only if, the subject has a poor diet, particularly inadequate in various important micronutrients (Benton \& Buts, 1990; Nelson, 1992; Eysenck \& Schoenthaler, 1997). In a randomized trial, Schoenthaler et al. (2000) showed that low-dose vitamin-mineral tablets improved non-verbal IQ in some children of low socioeconomic origin, but not in adequately nourished peers. In most of the studies demonstrating actual benefits, the improvement was observed in non-verbal intelligence tests but not in verbal intelligence tests. According to Benton (2001), a selective enhancement of non-verbal intelligence following supplementation reflects basic brain functions that are susceptible to influence by the diet.

The beneficial effect of micronutrient supplementation on IQ is by no means universal; however, sub-populations of children and adolescents whose diet is highly deficient in vitamins and minerals could benefit from supplementation (Schoenthaler \& Bier, 1999). Once more in this field, it appears that supplementation of certain nutrients does not induce cognitive enhancement per se, but rather may reverse, in certain individuals, the adverse effects of poor nutritional status. There is no evidence that healthy, well-fed young persons can benefit intellectually from acute micronutrient administration (Schoenthaler \& Bier, 1999).

\section{Discussion}

A number of recent well-designed studies suggest a potential role of certain nutrients, or elements of eating patterns, in cognitive functioning in children and adolescents. These works indicate that the brain is sensitive to moment-tomoment metabolic changes associated with the pattern of meals and fasting, and also to long-term nutritional status. In several instances, it has been revealed that the clearest effects of nutritional manipulations on cognitive efficiency and behaviour are obtained in young people with poor nutritional status. These observations confirm that poor nutritional status is likely to have deleterious influence on both cognition and behavioural adaptation. Corrective nutritional interventions in these unfortunate cases can only reverse the negative impact of inadequate diets. This underlines the unquestioned necessity of making adequate nutrition available to all youngsters, to prevent intellectual and behavioural problems of potentially long-lasting negative influence.

Besides obvious cases of inadequate dietary status, it is not clear that any particular nutrient or meal is likely to have unquestionable enhancing effects on the cognition or behaviour of well-nourished young people. Even having breakfast has inconsistent effects in well-nourished young people with good mental ability. It may not be possible to enhance cognition or behaviour through acute dietary interventions in young people whose excellent nutritional status results from sound regular dietary habits. This is probably what most of us would wish for our own children, and as a consequence, for all children. Encouraging the intake of a varied diet that includes numerous foods of good nutritional content, according to a sound meal pattern (with regular intake of a hearty 
breakfast and perhaps nutritionally valuable snacks), seems the optimal strategy to make sure that young people will have the best possible behavioural and cognitive functioning. It remains to be demonstrated if, indeed, enhanced cognition could be facilitated acutely under circumstances of demanding mental effort, by the intake of foods that would optimize the availability of fuel to the brain structures involved. More research is needed in this field.

It should be remembered also that while cognition and behaviour can be affected in young people by nutritional factors, many other aspects of their environment will modulate the effects of good nutrition. It should not be forgotten that scholastic achievement and successful integration into a social group also depend on numerous individual (e.g. psychological, emotional), familial and social factors. These reservations being made, it is unquestionable that nutrition can play an important role in the success of young people in the performance of these crucial adaptations.

\section{Acknowledgements}

This work was supported by a grant from the Nutritional Needs of Children Task Force of the European branch of the International Life Sciences Institute (ILSI Europe). Industry members of this task force are Barilla, CocaCola, Danone Vitapole, Friesland Coberco, Masterfoods, Nestlé and Numico. Further information about ILSI Europe can be obtained from $+32(0) 27710014$ or info@ilsieurope.be. The opinions expressed herein are those of the authors and do not necessarily represent the views of ILSI and ILSI Europe.

\section{References}

American Psychiatric Association (1994) Diagnostic and Statistical Manual of Mental Disorders, 4th ed. Washington, DC: American Psychiatric Association.

Behar D, Rapaport JL, Adams AA, Berg CK \& Cornblath M (1984) Sugar challenge testing with children considered behaviourally 'sugar active'. Nutr Behav 1, 277-288.

Benton D (2001) Micro-nutrient supplementation and the intelligence of children. Neurosci Biobehav Rev 25, 297-309.

Benton D \& Buts JP (1990) Vitamins/mineral supplementation and intelligence. Lancet 335, 1158-1160.

Benton D \& Owens DS (1993) Blood glucose and human memory. Psychopharmacology 113, 83-88.

Benton D \& Roberts G (1988) Effect of vitamin and mineral supplementation on intelligence in a sample of schoolchildren. Lancet 1, 140-143.

Benton D, Brett V \& Brain PF (1987) Glucose improves attention and reaction to frustration in children. Biol Psychol 24, 95-100.

Benton D, Griffiths S \& Haller J (1997) Thiamin supplementation, mood and cognitive functioning. Psychopharmacology 129, 66-71.

Benton D, Ruffin MP, Lassel T, Nabb S, Messaoudi M, Vinoy S, Desor D \& Lang V (2003) The delivery rate of dietary carbohydrates affects cognitive performance in both rats and humans. Psychopharmacology 166, 86-90.

Chandler AMK, Walker SP, Connolly K \& Grantham-McGregor SM (1995) School breakfast improves verbal fluency in undernourished Jamaican children. J Nutr 125, 894-900.
Colgan M \& Colgan L (1984) Do nutrient supplements and dietary changes affect learning and emotional reactions of children with learning difficulties? A controlled series of 15 cases. Nutr Health 3, 69-77.

Connors CK \& Blouin AG (1983) Nutritional effects on behaviour of children. J Psychiatr Res 17, 198-201.

Craft S, Zallen G \& Baker LD (1992) Glucose and memory in mild senile dementia of the Alzheimer type. J Clin Exp Neuropsychol 14, 253-267.

Craft S, Murphy S \& Wenstrom J (1994) Glucose effects on complex memory and non-memory tasks: the influence of age, sex, and glucoregulatory response. Psychobiology 22, 95-105.

Craft S, Newcomer J, Kanne S, Dagogo-Jack S, Cryer P, Sheline Y, Luby L, Dagogo-Jack A \& Alderson A (1996) Memory improvement following induced hyperinsulinemia in Alzheimer's disease. Neurobiol Aging 17, 123-136.

Crombie IK, Todman J, McNeill G, Florey C, Menzies IT \& Kennedy RA (1990) Effect of vitamin and mineral supplementation on verbal and non-verbal reasoning of schoolchildren. Lancet 311, 744-747.

Crook WG (1974) An alternative method of managing the hyperactive child. Paediatrics 5, 46-56.

Deheeger M, Rolland-Cachera MF \& Fontvieille AM (1997) Physical activity and body composition in 10 year old French children: linkages with nutritional intake? Int J Obes Relat Metab Disord 21, 372-379.

Dickie NH \& Bender AE (1982) Breakfast and performance in schoolchildren. Br J Nutr 48, 483-496.

Donohoe RT \& Benton D (1999) Cognitive functioning is susceptible to the level of blood glucose. Psychopharmacology $\mathbf{1 4 5}$, $378-385$.

Eysenck HJ \& Schoenthaler S (1997) Raising IQ level by vitamin and mineral supplementation. In Intelligence, Heredity and Environment, pp. 363-392 [RJ Sternberg and EL Grigorenko, editors]. Cambridge: Cambridge University Press.

Feingold FB (1977) Behavioral disturbances linked to the ingestion of food additives. Del Med J 49, 89-94.

Ferguson HB, Stoddart C \& Simeon PG (1986) Double blind challenge studies of behavioural and cognitive effects of sucrose-aspartame ingestion in normal children. Nutr Rev 44, Suppl., 144-150.

Foster JK, Lidder PG \& Sünram SI (1998) Glucose and memory: fractionation of enhancement effects. Psychopharmacology 137, 259-270.

Gibson EL \& Green MW (2002) Nutritional influences on cognitive function: mechanisms of susceptibility. Nutr Res Rev 15, 169-206.

Hoyer S (1997) Models of Alzheimer's disease: cellular and molecular aspects. J Neural Transm 49, Suppl., 11-21.

Kanarek R (1997) Psychological effects of snacks and altered meal frequency. Br J Nutr 77, Suppl. 1, S105-S120.

Kanarek RB \& Swinney D (1990) Effects of food snacks on cognitive performance in male college students. Appetite 14, 15-27.

Kennedey DO \& Scholey AB (2000) Glucose administration, heart rate and cognitive performance: effects of increasing mental effort. Psychopharmacology 149, 63-71.

Logue AW (1991) The Psychology of Eating and Drinking. An Introduction, 2nd ed. New York, NY: WH Freeman.

Mahan LK, Chase M, Furukawa CT, Sulzacher S, Shapiroo GG, Pierson W \& Bierman CW (1988) Sugar 'allergy' and children's behaviour. Ann Allergy 61, 453-458.

Manning CA, Honn VS, Stone WS, Jane JS \& Gold PE (1998) Effects of glucose ingestion on cognition in adults with Down's syndrome. Neuropsychology 12, 479-484.

Messier C \& Gagnon M (1996) Glucose regulation and cognitive functions: relation to Alzheimer's disease and diabetes. Behav Brain Res 75, 1-11. 
Michaud C, Musse N, Nicolas JP \& Méjean L (1991) Effects of breakfast size on short-term memory, concentration, mood and blood glucose. J Adolesc Health 12, 53-57.

Nelson M (1992) Vitamin and mineral supplementation and academic performance in schoolchildren. Proc Nutr Soc 51, $303-313$.

Nelson M, Naismith DJ, Burley V, Gatenby SJ \& Geddes N (1990) Nutrient intakes, vitamin-mineral supplementation and intelligence in British schoolchildren. Br J Nutr 64, 13-22.

Pollitt E (1998) Breakfast, Cognition, and School Learning. Proceedings of a symposium held in Napa, California. August $28-$ 30, 1995. Am J Clin Nutr 67, Suppl.

Pollitt E, Leibel RL \& Greenfield D (1981) Brief fasting, stress and cognition in children. Am J Clin Nutr 34, 1526-1533.

Pollitt E, Lewis NL, Garza C \& Shulman RJ (1983) Fasting and cognitive function. J Psychiatr Res 17, 169-174.

Prinz RJ \& Riddle DB (1986) Association between nutrition and behaviour. Nutr Rev 44, Suppl., 151-158.

Prinz RJ, Roberts WA \& Hantman E (1980) Dietary correlates of hyperactive behaviour in children. J Consult Clin Psychol 47, 760-769.

Rapp DJ (1978) Does diet affect hyperactivity? J Learn Disabil 11, 383-389.

Rodriguez WA, Horne CA \& Padilla JL (1999) Effects of glucose and fructose on recently reactivated and recently acquired memories. Prog Neuropsychopharmacol Biol Psychiatry 23, $1285-1317$.

Rosen LA, Booth SR, Bender ME, McGrath ML, Sorrel S \& Drabman R (1988) Effects of sugar (sucrose) on children's behaviour. J Consult Clin Psychol 56, 583-589.

Roshon MS \& Hagen RL (1989) Sugar consumption, locomotion, task orientation, and learning in preschool children. J Abnorm Child Psychol 17, 349-357.

Saravis S, Schachar R, Zlotkin S, Leiber LA \& Anderson GH (1990) Aspartame: effects on learning, behaviour and mood. Paediatrics 86, 75-80.

Schoenthaler SJ \& Bier ID (1999) Vitamin-mineral intake and intelligence: a macrolevel analysis of randomized controlled trials. J Altern Complement Med 5, 125-134.
Schoenthaler SJ, Amos SP, Doraz WF, Kelly MA \& Wakefield J (1991) Controlled trial of vitamin-mineral supplementation on intelligence and brain function. Pers Individ Dif 12, 343-350.

Schoenthaler SJ, Bier ID, Young K, Nichols D \& Jansenns S (2000) The effect of vitamin-mineral supplementation on the intelligence of American schoolchildren: a randomized, double blind placebo-controlled trial. J Altern Complement Med 6, 31-35.

Simeon T \& Grantham-McGregor S (1989) Effects of missing breakfast on the cognitive functions of school children with differing nutritional status. Am J Clin Nutr 49, 646-653.

Swanson JM \& Kinsbourne M (1980) Food dyes impair performance of hyperactive children on a laboratory learning test. Science 207, 1485-1487.

Weiss B, Williams JH, Margen S, et al. (1980) Behavioral responses to artificial food colors. Science 207, 1487-1489.

Wender EH \& Solanto MV (1991) Effects of sugar on aggressive and inattentive behaviour in children with attention deficit disorder upon identification of targets in a non-search task. Percept Psychophysiol 16, 143-149.

Wilens T, Pelham W, Stein M, et al. (2003) ADHD treatment with once-daily OROS methylphenidate: interim 12-month results from a long-term open-label study. J Am Acad Child Adolesc Psychiatry 42, 424-433.

Wolraich M, Milich R, Stumbo P \& Schultz F (1985) Effects of sucrose ingestion on the behaviour of hyperactive boys. J Pediatr 106, 675-682.

Wolraich M, Stumbo P, Milich R, Chenard C \& Schultz F (1986) Dietary characteristics of hyperactive and control boys and their behavioural correlates. J Am Diet Assoc 84, 500-504.

Wolraich ML, Greenhill LL, Pelham W, et al. (2001) Randomized, controlled trial of oros methylphenidate once a day in children with attention-deficit/hyperactivity disorders. Pediatrics 108, 883-892.

Wyon DP, Abrahamsson L, Järtelius M \& Fletcher RJ (1997) An experimental study of the effects of energy intake at breakfast on the test performance of 10-year-old children in school. Int J Food Sci Nutr 48, 5-12. 